\title{
A comparative study of different transformer connections for railway power supply- mitigation of voltage unbalance
}

Firat, Gurkan; Yang, Guangya; Ali Hussain Al-Ali, Haider

Published in:

Proceedings of 10th International Conference on Advances in Power System Control, Operation \& Management (APSCOM 2015)

Link to article, DOI:

10.1049/ic.2015.0216

Publication date:

2015

Document Version

Peer reviewed version

Link back to DTU Orbit

Citation (APA):

Firat, G., Yang, G., \& Ali Hussain Al-Ali, H. (2015). A comparative study of different transformer connections for railway power supply- mitigation of voltage unbalance. In Proceedings of 10th International Conference on Advances in Power System Control, Operation \& Management (APSCOM 2015) IEEE. https://doi.org/10.1049/ic.2015.0216

\section{General rights}

Copyright and moral rights for the publications made accessible in the public portal are retained by the authors and/or other copyright owners and it is a condition of accessing publications that users recognise and abide by the legal requirements associated with these rights.

- Users may download and print one copy of any publication from the public portal for the purpose of private study or research.

- You may not further distribute the material or use it for any profit-making activity or commercial gain

- You may freely distribute the URL identifying the publication in the public portal 


\section{A COMPARATIVE STUDY OF DIFFERENT TRANSFORMER CONNECTIONS FOR RAILWAY POWER SUPPLY- MITIGATION OF VOLTAGE UNBALANCE}

\author{
Gurkan Firat \\ Dept. of Electrical Engineering \\ Technical University of Denmark \\ Email:firatgurkan@gmail.com
}

\author{
Guangya Yang \\ Dept. of Electrical Engineering \\ Technical University of Denmark \\ Email: gyy@elektro.dtu.dk
}

\author{
Haider Ali Hussain Al-Ali \\ Electrification Program \\ Banedanmark \\ Email: haal@bane.dk
}

\begin{abstract}
The railway represents a large power consumer that can cause uneven loading of the phases in the high voltage grid. These unbalanced loads supplied by the utility may lead to voltage unbalance problems in the system and thereby affects the other consumers connected to the same network. It is fact that, voltage unbalance appears mainly as a result of unbalanced currents at the points of common coupling drawn by unevenly distributed loads. Because of a significant amount of negative sequence current injected to the system, the power system components will suffer from consequent negative effects such as overheating, additional losses of lines and transformers, interference with communication systems etc. This paper presents a comparative study of some transformer connections which commonly used in railway supplying AC traction loads, for voltage unbalance mitigations. Simulations for comparison of transformers are carried out and the results are also compared with the values obtained by the voltage unbalance estimation formulas.
\end{abstract}

Keywords: Electrified railways, traction loads, voltage unbalance, transformer connections

\section{INTRODUCTION}

Electrification of a railway line implies that the line can be operated by electric trains other than diesel. Electrification involves large investments but operating costs are lower than diesel as propulsion and maintenance are cheaper. In Denmark, since the first electrified line opened for operation in 1986, it has been a wish to extend the electrification to the rest of the country. The main lines belonging to the Danish railway company 'Banedanmark (BDK)' are basically supplied by $50 \mathrm{~Hz} \mathrm{AC}$ at $27.5 \mathrm{kV}$. The power transformers of the traction power substations are fed from two phases of $132 / 150 \mathrm{kV}$ transmission grids, and have a direct connection with the railway substations as shown in Figure 1-1. The loads are generally unevenly distributed on different phases. Recently, an electrification project has initiated aiming to electrify the existing railway line in order to run electrical train to reduce the diesel trains number in the future. This means that the number of railway traction substations will increase, and existing power supply systems will need some change or modification to deal with the subsequent voltage unbalance problems by the increased traction loads.
In order to stay within the limits specified by the energy provider and to guarantee optimum functioning of the railway operation, it is mandatory for the railway operator to look for viable solutions for voltage unbalance compensation.

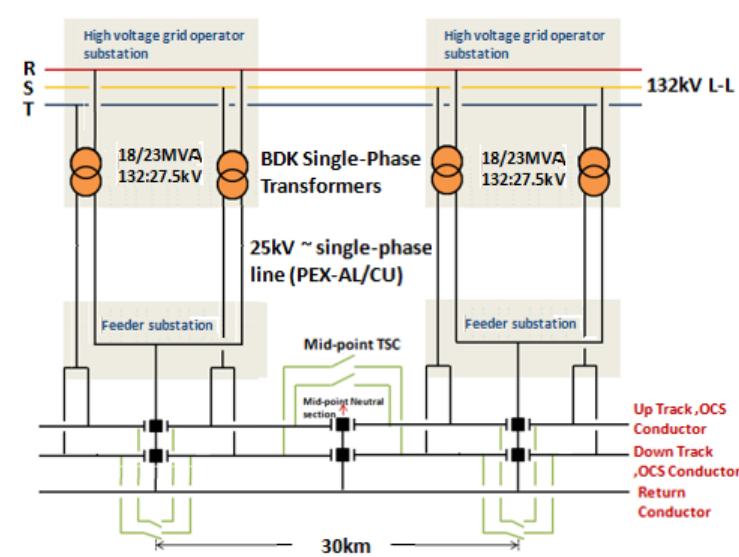

Figure 1-1: BDK's railway feeder and substation scheme

This paper studies the voltage unbalance problems due to unbalanced traction loads under different transformer connections. The simulations are performed by using actual traction load data (for 7 days) provided by BDK from one of its traction power substations. The data will be the reference data to determine the voltage unbalance under different short circuit power level at the point of common coupling (PCC). Then different transformer configurations are compared in regards of the impact on voltage unbalance they introduce.

\section{NATURE OF VOLTAGE UNBALANCE}

A three-phase power system is assumed to be symmetrical or balanced if the voltages and the currents have the same amplitude and each has a phase difference of $120^{\circ}$. Otherwise, the power system is called as asymmetrical or unbalanced.

In fact, a perfectly symmetrical power system does not occur due to some internal effects such as; transformer windings, multiple transmission lines on each transmission line tower (mutual coupling). Under normal operating conditions, these are some of the well-known reasons causing system unbalance, but in practice the main sources of unbalance are unevenly distributed phase-to-phase connected loads [7].

Unbalanced voltages can be very severe for the equipment and power network itself. Because the 
small changes in the balanced phase voltages could lead to larger amount of unbalance in the phase currents. This shows itself as heat and loss and makes the system less stable [7].

\subsection{Mitigation Techniques}

To be able to reduce the effects of unbalance, in case there is a weak high-voltage transmission network, several techniques can be applied depending on the technological justification. A basic solution can be achieved by distributing the loads evenly between the different phases. However, this method alone may not be sufficient enough in railway as it depends on different traffic intensity occurring at each substation.

Therefore, other actions are needed to be taken to mitigate the unbalance problem. The possible solutions can be categorized in two different groups. First one is based on transformer connections, i.e. passive solutions. These types of transformers are widely used in electrified railway systems as a load balancer. In this paper some wellknown transformer connections are analyzed.

The second one (not in the scope of this paper) is based on controllable high voltage power electronic equipment, i.e. active solutions. Conventional Static Var Compensators (SVC) or recently explored Voltage Source Converters (SVC Light) are the most commonly used tools as a load balancer [6].

\section{TRANSFORMER CONNECTIONS}

\subsection{Single-Phase transformer}

Single-phase transformers are used as a conventional traction power supply system in railway applications. It is used to transforms $132 \mathrm{kV}$ grid voltage into $27.5 \mathrm{kV}$ catenary voltage. Figure 3-1 shows a basic schematic of a single phase traction transformer and its phasor diagram, respectively. In Denmark, all existing traction transformers are conventional two phase connected single phase transformers.

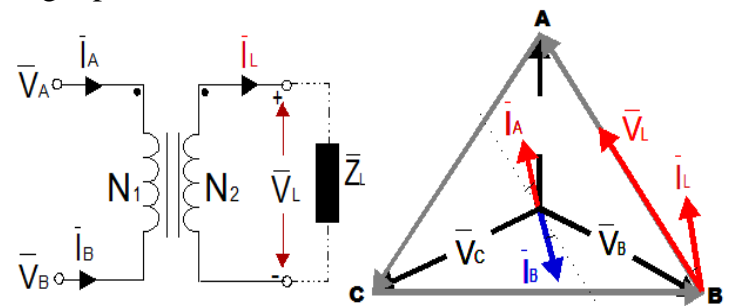

Figure 3-1: A basic single phase connection and its phasor diagram [4][5]

The relations between primary and secondary voltages and currents of a single-phase transformer are shown in the following equations [4]:

$\bar{V}_{A B}=\bar{V}_{A}-\bar{V}_{B}=\frac{N_{1}}{N_{2}} \bar{V}_{L}$
$\bar{I}_{A}=-\bar{I}_{B}=\frac{N_{2}}{N_{1}} \bar{I}_{L}$ and $\bar{I}_{C}=0$
As the power is drawn from only two phases, it may give rise to a quite large voltage unbalance in the transmission. It may also cause an excessive voltage drop due to its high internal impedance for railway applications. On the other hand, the transformers can without any problem be overloaded by a factor of 2 of its rated power for short time intervals [2].

\subsection{Scott transformer}

Scott transformer is one of the most commonly known transformer type used with the purpose of mitigating voltage unbalance problems. It consists of two single-phase transformers connected in a special way as illustrated in Figure 3-2 with its phasor diagram.

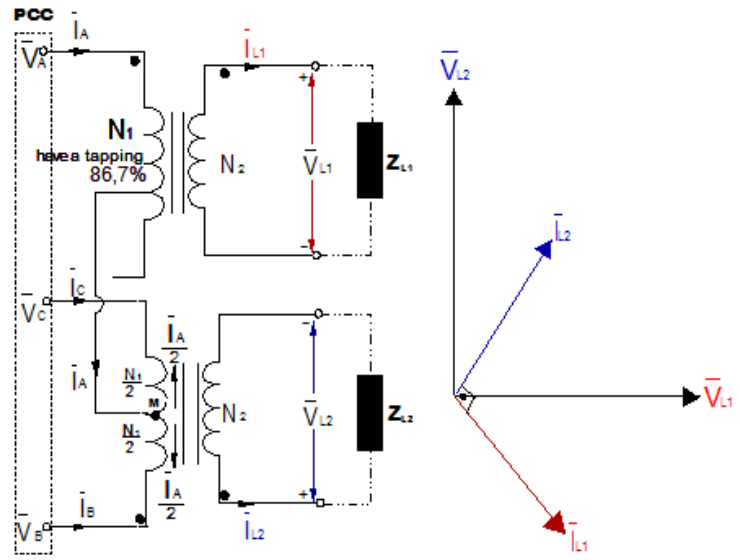

Figure 3-2: Scott connection and its phasor diagram [4][5]

Scott transformer has the capability of converting a balanced three-phase system to a balanced twophase system. If the two loads on the secondary side are balanced then the line currents drawn from the three-phase network will also be balanced.

The relations between the primary and the secondary voltages and currents are shown in the following equations [4]:

$$
\begin{gathered}
\bar{V}_{A B}=\frac{N_{1}}{2 N_{2}}\left(\sqrt{3} \bar{V}_{L 1}-\bar{V}_{L 2}\right) ; \bar{I}_{A}=\frac{N_{2}}{N_{1}} \frac{2}{\sqrt{3}} \bar{I}_{L 1} \\
\bar{V}_{B C}=\frac{N_{1}}{N_{2}} \bar{V}_{L 2} ; \bar{I}_{B}=\frac{N_{2}}{N_{1}}\left(\bar{I}_{L 2}-\frac{1}{\sqrt{3}} \bar{I}_{L 1}\right) \\
\bar{V}_{C A}=\frac{-N_{1}}{2 N_{2}}\left(\sqrt{3} \bar{V}_{L 1}+\bar{V}_{L 2}\right) ; \\
\bar{I}_{C}=\frac{-N_{2}}{N_{1}}\left(\bar{I}_{L 2}+\frac{1}{\sqrt{3}} \bar{I}_{L 1}\right)
\end{gathered}
$$

\subsection{Leblanc-connected transformer}

Similar as the Scott transformer, LeBlanc connected transformer is also used for the same goals of transforming balanced two-phase system to balanced three-phase system or vice versa. The main difference between Scott and LeBlanc connected transformer is the number of core used for windings. Unlike Scott transformer, LeBlanc transformer is constructed on three-legged core. Figure 3-3 shows the connection arrangements of a LeBlanc transformer and its currents phasor diagram. 
The relations between the primary and secondary voltages and currents are shown in the following equations [4]:

$\bar{V}_{A B}=\frac{-N_{1}}{N_{2}}\left(\frac{\sqrt{3}}{2} \bar{V}_{T}+\frac{3}{4} \bar{V}_{M}\right) ; \bar{I}_{A}=-\frac{N_{2}}{N_{1}} \frac{2}{\sqrt{3}} \bar{I}_{T}$

$\bar{V}_{B C}=\frac{N_{1}}{N_{2}} \frac{3}{2} \bar{V}_{M} ; \bar{I}_{B}=\frac{N_{2}}{N_{1}}\left(\bar{I}_{M}+\frac{1}{\sqrt{3}} \bar{I}_{T}\right)$

$\bar{V}_{C A}=\frac{N_{1}}{N_{2}}\left(\frac{\sqrt{3}}{2} \bar{V}_{T}-\frac{3}{4} \bar{V}_{M}\right)$;

$$
\bar{I}_{C}=\frac{N_{2}}{N_{1}}\left(\frac{1}{\sqrt{3}} \bar{I}_{T}-\bar{I}_{M}\right)
$$

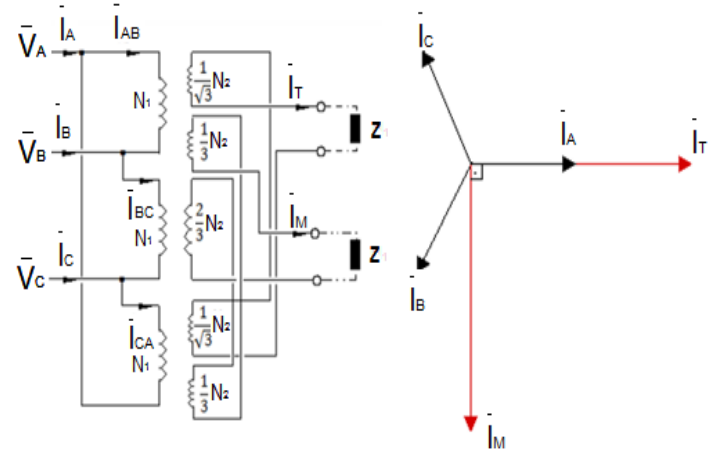

Figure 3-3: Leblanc connection and its phasor diagram [4][5]

\section{4. $\mathrm{V} / \mathrm{V}$ connection}

$\mathrm{V} / \mathrm{V}$ transformer is another well-known specially connected transformer used in railway applications. The circuit diagram of $\mathrm{V} / \mathrm{V}$ connected transformer and its phasors are shown in Figure 3-4.
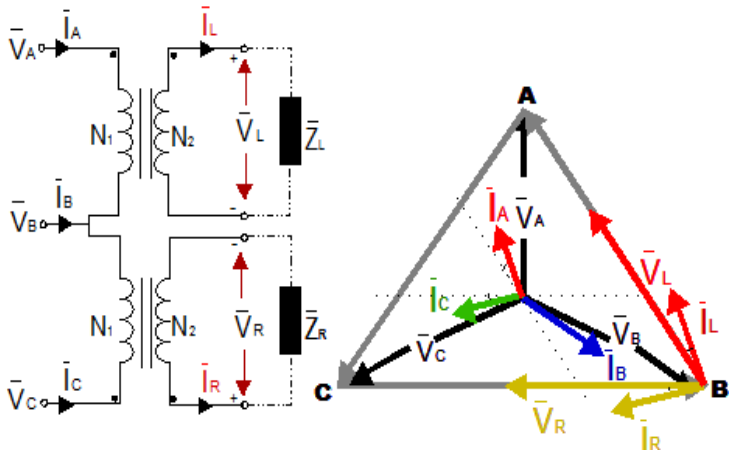

Figure 3-4: V/V connection and its phasor diagram [4][5]

It is composed of two single-phase transformers whose primary sides connected to two phases, such as $A B$ and $B C$, of the three phase high voltage grid. The aim is to distribute the single-phase load evenly between three phases.

The relationships between the primary and secondary voltages and currents are given as [4]:

$$
\begin{aligned}
& \bar{V}_{A B}=\frac{N_{1}}{N_{2}} \bar{V}_{L} ; \bar{I}_{A}=\frac{N_{2}}{N_{1}} \bar{I}_{L} \\
& \bar{V}_{B C}=-\frac{N_{1}}{N_{2}} \bar{V}_{R} ; \bar{I}_{B}=-\frac{N_{2}}{N_{1}}\left(\bar{I}_{L}+\bar{I}_{R}\right)
\end{aligned}
$$

$$
\bar{V}_{C A}=\frac{N_{1}}{N_{2}}\left(\bar{V}_{R}-\bar{V}_{L}\right) ; \quad \bar{I}_{C}=\frac{N_{2}}{N_{1}} \bar{I}_{R}
$$

\subsection{Wye/Delta connection}

Wye/Delta is one of the transformer connections used in traction systems for load balancing. It is obtained by combining three single-phase transformer banks as delta at the secondary and wye at the primary. The ratio of the primary to secondary line voltage is $\sqrt{3}$ times the transformer's turn ratio with a $30^{\circ}$ phase difference. Figure 3-5 shows the circuit arrangement of Wye/Delta transformer and its phasor diagram.

The voltage and current relationships between the primary and secondary side is given as [4]:

$$
\begin{aligned}
& \bar{V}_{A B}=\frac{N_{1}}{N_{2}}\left(\bar{V}_{L}+\bar{V}_{R}\right) ; \bar{I}_{A}=\frac{1}{2} \frac{N_{2}}{N_{1}}\left(\bar{I}_{L}+\bar{I}_{R}\right) \\
& \bar{V}_{B C}=\frac{N_{1}}{N_{2}}\left(-2 \bar{V}_{R}+\bar{V}_{L}\right) ; \bar{I}_{B}=\frac{1}{2} \frac{N_{2}}{N_{1}}\left(\bar{I}_{L}+\bar{I}_{R}\right) \\
& \bar{V}_{C A}=\frac{N_{1}}{N_{2}}\left(\bar{V}_{R}-2 \bar{V}_{L}\right) ; \bar{I}_{C}=\frac{1}{2} \frac{N_{2}}{N_{1}}\left(\bar{I}_{R}-\bar{I}_{L}\right)
\end{aligned}
$$

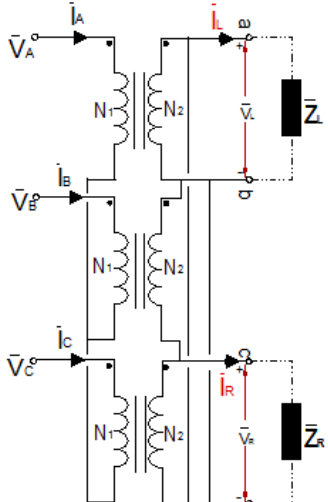

Figure 3-5: Wye/Delta connection and its phasor diagram [4][5]

\subsection{Delta/Delta Connection}

The main advantage of this connection is that even if one of the three transformers is disabled, the system can still maintain to operate as an open delta but with reduced available capacity.

Figure 3-6 shows the circuit arrangement of a Delta/Delta transformer and its phasor diagram. The current and voltage relationships of this type of connection are identical with $\mathrm{V} / \mathrm{V}$ connection.

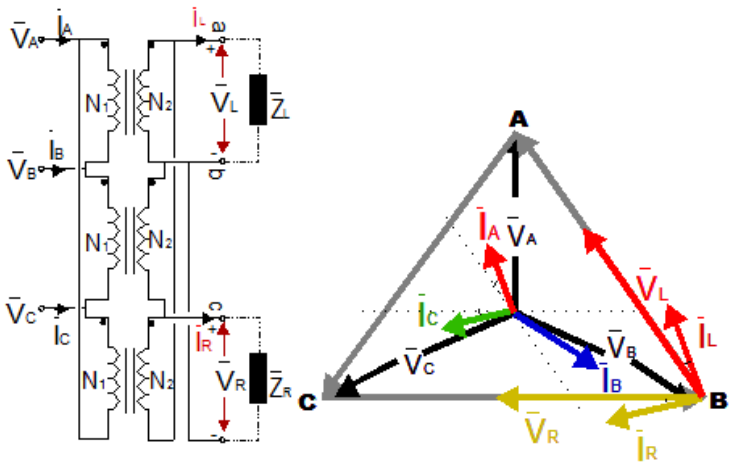

Figure 3-6: Delta/Delta connection and its phasor diagram [4][5] 


\section{VUF (\%) ESTIMATION FORMULAS}

VUF (Voltage Unbalance Factor) is widely used by most of the utilities to keep the unbalance injections under a certain level at PCC point. Table 4-1 shows the estimation formulas (derived by symmetrical components [1]) used for calculating maximum VUF (\%) for some types of transformer connections. The benefit of the estimation formulas is that it gives a quick and straightforward way to compute the maximum VUF (\%) at a PCC.

In the table, $S_{1 \varnothing}=S_{L 1}+S_{L 2}$ is the total load transformer supplies. $S_{L 1}$ represents the MVA load from one terminal and $S_{L 2}$ is the MVA load from another terminal. $\mathrm{k}$-is the factor of load distribution defined as $S_{L 1}=k S_{1 \emptyset} \quad$ and $\quad S_{L 2}=(1-$ $k) S_{1 \varnothing} \cdot S_{S c(3 \emptyset)}$ is the 3-phase short circuit power (SSP) at the PCC. It is an important parameter when designing a power system. For a better voltage regulation, the short circuit level is expected to be sufficiently higher.

Table 4-1: Vuf (\%) Estimation Formulas [1]

\begin{tabular}{|c|c|c|c|c|}
\hline Connections & \multicolumn{4}{|c|}{ Voltage Unbalance Factor, VUF (\%) } \\
\hline Single-phase & \multicolumn{4}{|c|}{$\left|\frac{V_{2}}{V_{1}}\right|=\frac{S_{1 \varnothing}}{S_{s c(3 \emptyset)}} * 100$} \\
\hline Scott & $\left|\frac{V_{2}}{V_{2}}\right|=|1-2 k|$ & $\frac{S_{1 \emptyset}}{S}$ & \multicolumn{2}{|l|}{$* 100$} \\
\hline Le Blanc & $\left|\frac{V_{2}}{V_{1}}\right|=|1-2 k| \mid$ & $\frac{S_{1 \emptyset}}{S_{s c(3 \emptyset)}}$ & \multicolumn{2}{|l|}{$* 100$} \\
\hline$V-V$ & \multicolumn{2}{|c|}{$\left|\frac{V_{2}}{V_{1}}\right|=\sqrt{3 k^{2}-3 k+1}$} & $\frac{S_{1 \varnothing}}{S_{s c(3 \emptyset)}}$ & * 100 \\
\hline Wye-delta & \multicolumn{2}{|c|}{$\left|\frac{V_{2}}{V_{1}}\right|=\sqrt{3 k^{2}-3 k+1} \mid$} & $\frac{S_{1 \emptyset}}{S_{s c(3 \emptyset)}}$ & * 100 \\
\hline Delta-delta & \multicolumn{2}{|c|}{$\left|\frac{V_{2}}{V_{1}}\right|=\sqrt{3 k^{2}-3 k+1}$} & $\frac{S_{1 \varnothing}}{S_{s c(3 \emptyset)}}$ & * 100 \\
\hline
\end{tabular}

\section{TRACTION LOAD FOR SIMULATIONS}

As stated earlier, in this paper a traction power substation is used as case study to investigate possible solutions for voltage unbalance problems. Figure 5-1 illustrates the traction loads at the power substation (KAM), which is located at utility substation (USS), and its connection schematic on the catenary side, at ROF (RSS).

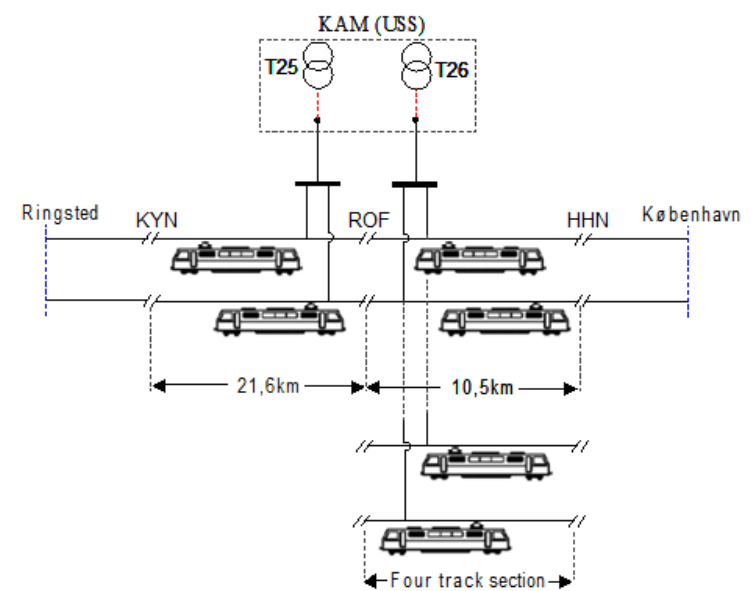

Figure 5-1: Traction loads connected to ROF feeder substation
As the figure indicates, there are two single-phase transformers (both connected to Phase A and Phase B), T25 and T26, at the power substation and each transformer is rated at $23 \mathrm{MVA}$ and feeds power to different sections. The four track section from ROF to HHN is fed by transformer T25.

Figure 5-2 and 5-3 shows the load consumption at PCC by transformer T25 and T26 during a one week period. The measurements are taken at the primary side of each traction transformer and collected every 1 second.

As it can be seen from the data tips on Figure 5-2 and 5-3, the maximum power drawn by T25 occurs at 183403s of 23.26 MVA, and at the very same instant the power drawn by T26 is 2.37 MVA. Thus, the maximum total power drawn at the PCC during one week period would be 25.63MVA. This value can be used to calculate max. VUF (\%) in accordance with the voltage unbalance emission limits for installations from IEC/TR 61000-3-13 [3].

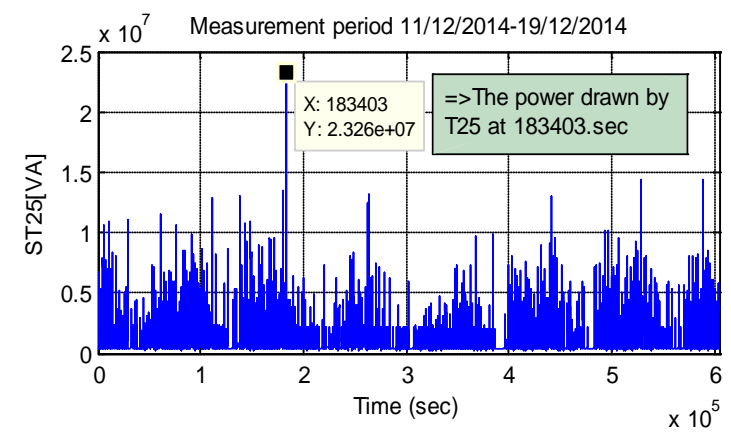

Figure 5-2: Load consumption at KAM T25 (at PCC) during one week period.

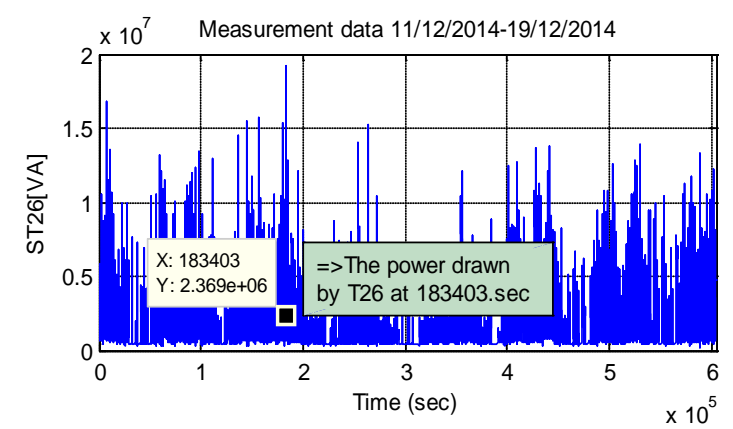

Figure 5-3: Load consumption at KAM T26 (at PCC) during one week period.

According to IEC/TR 61000-3-13, the maximum VUF (\%) that the railway operator is allowed to introduce at a specific PCC is calculated by the following formula:

$E_{u i}=E_{u} \cdot\left(\sqrt[\alpha]{\frac{s_{i}}{s_{\max }}}\right)$

where,

$\boldsymbol{E}_{\boldsymbol{u} \boldsymbol{i}}$ - The limit for the contribution to voltage unbalance for each installation at a given point in the transmission grid.

$\boldsymbol{E}_{\boldsymbol{u}}$ - The limit for max. voltage unbalance that energy provider (Energinet.dk) can cope with. It is 
$1.4 \%$ at a given point in the transmission grid.

$\boldsymbol{S}_{\boldsymbol{i}}$ - The maximum instantaneous load in MVA for an installation in the given PCC.

$\boldsymbol{S}_{\boldsymbol{m a x}}$ - The maximum instantaneous load in MVA from $132 \mathrm{kV}$ USS, which is set to 100MVA.

$\boldsymbol{\alpha}$ - is set to 2, which takes the simultaneity into account among unbalances from several installations.

The max. VUF (\%) for the substation can then be calculated as,

$E_{u i}(\%)=(1.4 \%) \cdot\left(\sqrt[2]{\frac{25.63 M V A}{100 M V A}}\right)=0.71$

Again, according to Energinet.dk's regulations the customer can choose to wait for any necessary compensation until the load at the PCC reaches a level where the resultant maximum voltage unbalance exceeds the limit in more than $1 \%$ of a 7 days period. Taking this into account, $1 \%$ of the total duration for this case is calculated as $604800 \mathrm{~s} *(1 \%)=6048 \mathrm{~s}$.

\section{SIMULATION RESULTS}

Figure 6-1 shows the VUFs (\%) duration curve for a week at PCC by the current load profile. Only the part over the limit is shown. The short-circuit level is assume $1399 \mathrm{MVA}$.

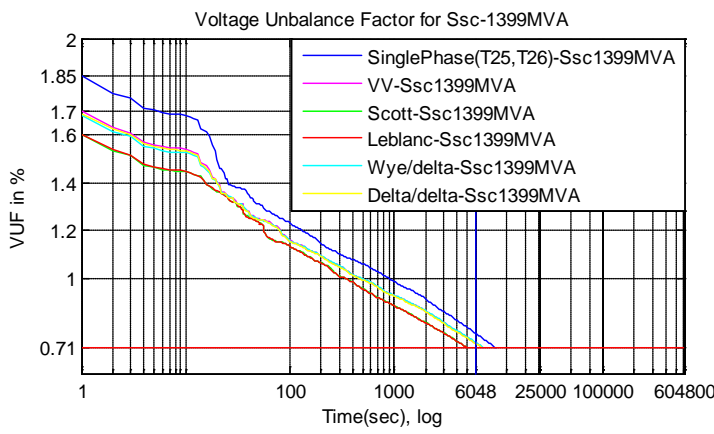

Figure 6-1: VUF (\%) for different transformers introduced by the load at SSP 1399 MVA

The purpose of changing short-circuit level is to study the VUF (\%) in case of an installation point has a lower short-circuit capacity than the studied substation however with the same load profile.

The red line in Figure 6-1 shows the maximum allowed VUF (\%), $E_{u i}(\%)=0.71$, which can be introduced by the current load. As long as the total duration over $0.71 \%$ is less than 6048 s, there will be no need for compensation. As it can be seen from Table 6-1, degree of voltage unbalance is substantially reduced by the $\mathrm{V} / \mathrm{V}$, Wye/delta and Delta/delta connected transformers compared to single phase connection. However, Scott and Leblanc connections give a better profile. It is obvious that, there is no need for compensation for Scott and Leblanc transformers as they reach the limit before $x=6048 s$. The duration difference between Scott and single phase is 4342s. With the present case, BDK will need to compensate VUF 3314s.

Table 6-1: Simulated maximum VUF (\%) values and durations from Figure 6-1.

\begin{tabular}{lcl}
\hline $\begin{array}{l}\text { Type of } \\
\text { transformers }\end{array}$ & $\begin{array}{c}\text { Maximum } \\
\text { VUF (\%) }\end{array}$ & $\begin{array}{l}\text { Duration } \\
\text { wutil } \\
\text { vUF }(9)=0,71\end{array}$ \\
\hline Leblanc & 1.604 & $\mathrm{x}=4972 \mathrm{sec}$ \\
Scott & 1.601 & $\mathrm{x}=5020 \mathrm{sec}$ \\
Delta-delta & 1.690 & $\mathrm{x}=6872 \mathrm{sec}$ \\
VV & 1.698 & $\mathrm{x}=7031 \mathrm{sec}$ \\
Wye-delta & 1.680 & $\mathrm{x}=7183 \mathrm{sec}$ \\
SinglePhase $/$ Kam & 1.846 & $\mathrm{x}=9362 \mathrm{sec}$ \\
\hline
\end{tabular}

Figure 6-2 corresponding to Table 6-2 shows the results obtained when the short-circuit level is 2581 MVA, which is the present short-circuit power level of the selected substation.

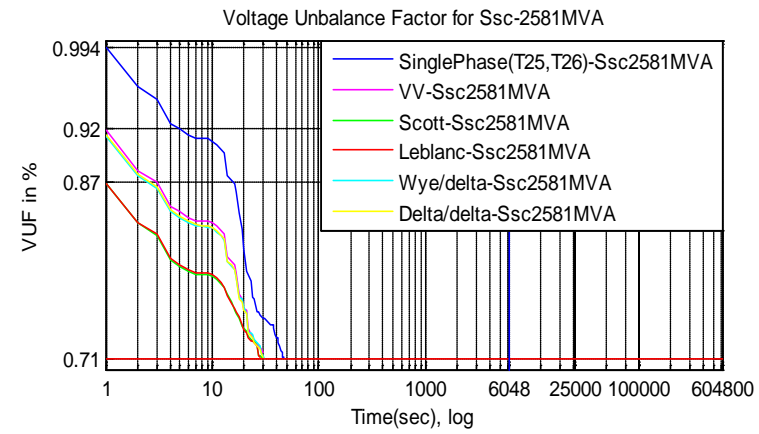

Figure 6-2: VUF (\%) for different transformer connections introduced by load at SSP $=2581 \mathrm{MVA}$

According to the results, everything looks fine even when single-phase connection is used. However, this case is valid only for the present load and short circuit power level. These conditions will probably not be the same in the near future with increasing of traction loads. This is because line speeds are expected to be increased, new lines will be electrified and thereby the loads will be increased. In that case Scott or Leblanc transformers would be the best choice.

Table 6-2: Simulated max. VUF (\%) values and durations from Figure 6-2

\begin{tabular}{lcc}
\hline $\begin{array}{l}\text { Type of } \\
\text { transformers }\end{array}$ & $\begin{array}{c}\text { Maximum } \\
\text { VUF (\%) }\end{array}$ & $\begin{array}{c}\text { Duration } \\
\text { vutil } \\
\mathrm{VUr}(9)=0,71\end{array}$ \\
\hline Leblanc & 0.8699 & $\mathrm{x}=28 \mathrm{sec}$ \\
\hline Scott & 0.8686 & $\mathrm{x}=30 \mathrm{sec}$ \\
Delta-delta & 0.9133 & $\mathrm{x}=30 \mathrm{sec}$ \\
\hline VV & 0.9175 & $\mathrm{x}=30 \mathrm{sec}$ \\
Wye-delta & 0.9116 & $\mathrm{x}=31 \mathrm{sec}$ \\
\hline SinglePhase/Kam & 0.9938 & $\mathrm{x}=47 \mathrm{sec}$ \\
\hline
\end{tabular}

The estimation formulas presented in Table 4-1 are also applied to determine the VUF (\%) introduced by the case-study for short circuit power level of 2581MVA to make a comparison with the VUF (\%) obtained by the simulations. Figure $6-3$ and Table 6-3 shows the compared graph and corresponding maximum VUF (\%), respectively. 
The results reveal that the estimated and simulated values are slightly different from each other. The difference is only around $7.5 \%$ for most of the cases except the single phase case. This means that the result from formulas could be corrected by increasing $7.5 \%$.

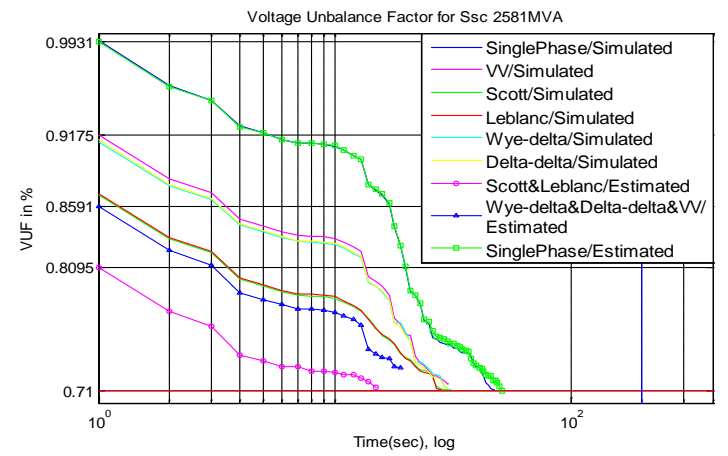

Figure 6-3: VUF (\%) for different transformers connections obtained by Simulation and Estimation Formulas

Table 6-3: Simulated and Estimated max. VUF (\%) values from Figure 6-3

\begin{tabular}{lcc}
\hline $\begin{array}{l}\text { Type of } \\
\text { transformers }\end{array}$ & $\begin{array}{l}\text { Maximum } \\
\text { Simulated } \\
\text { VUF(\%) }\end{array}$ & $\begin{array}{l}\text { Maximum } \\
\text { Estimated } \\
\text { VUF(\%) }\end{array}$ \\
\hline Leblanc & 0,8699 & 0,8095 \\
\hline Scott & 0,8686 & 0,8095 \\
Delta-delta & 0,9133 & 0,8591 \\
VV & 0,9175 & 0,8591 \\
Wye-delta & 0,9116 & 0,8591 \\
SinglePhase/Kam & 0,9938 & 0,9931 \\
\hline
\end{tabular}

Figure 6-4 shows the graph after estimated results are corrected by $7.5 \%$ (vuf(\%)+vuf(\%)*7.5\%) except the single phase connection. The maximum VUF (\%) values from Figure 6-4 are placed in Table 6-4 to be able to make a clearer comparison.

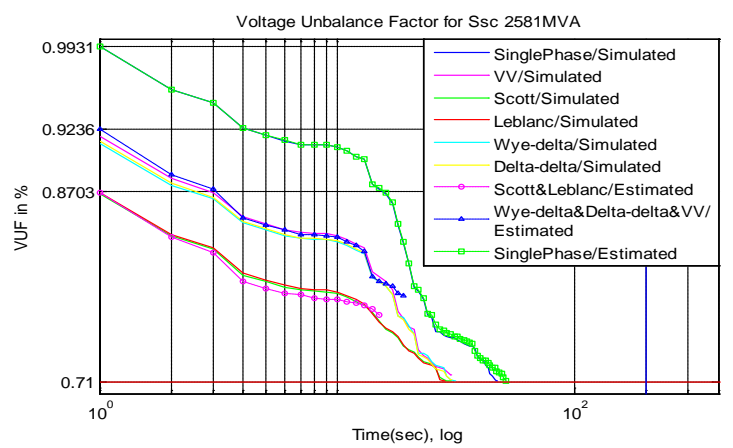

Figure 6-4: VUF (\%) for different type of transformers obtained by Simulations and Estimation Formulas (+7.5\% corrected)

It is obvious that the maximum values listed in Table 6-4 are almost the same. This means that the estimation formulas, after correction, can also be used as a quick and efficient way to calculate the maximum VUF (\%) introduced by different transformer configurations.
Table 6-4: Simulated and Estimated maximum VUF (\%) values from Figure 6-4

\begin{tabular}{lcc}
\hline $\begin{array}{l}\text { Type of } \\
\text { transformers }\end{array}$ & $\begin{array}{c}\text { Maximum } \\
\text { Simulated } \\
\text { VUF(\%) }\end{array}$ & $\begin{array}{c}\text { Maximum } \\
\text { Estimated } \\
\text { vUF(\%)+7,5\% } \\
\text { correction }\end{array}$ \\
\hline Leblanc & 0,8699 & 0,8703 \\
Scott & 0,8686 & 0,8703 \\
\hline Delta-delta & 0,9133 & 0,9236 \\
VV & 0,9175 & 0,9236 \\
Wye-delta & 0,9116 & 0,9236 \\
\hline SinglePhase/Kamstrup & 0,9938 & 0,9931 \\
\hline
\end{tabular}

\section{CONCLUSIONS}

The simulation results reveal that with the exception of the single-phase connection, the rest of the transformer connections introduced are capable of reducing voltage unbalance degree to a certain extent. Especially, Scott and Leblanc connections can be quite effective if they combined with a reasonable train dispatch schedule [1].

For short circuit levels below 1399 MVA a different solution such as unbalance compensators should be considered as all of the transformer configurations exceed the allowed limit with the example load profile. Although there is no need for compensation for the short circuit levels above 1399 MVA with the present load, situations might not be the same in the future depending on the demand level. If it is also accompanied by a really weak power network, alternative solutions would be unavoidable.

\section{REFERENCES}

[1] Bin Kwie-Chen, Bing Song Guo. "Three Phase Models of Specially Connected Transformers." Taipei, Taiwan: IEEE Transactions on Power Delivery, Vol 11, No.1, January 1996.

[2] Copenhagen-Ringsted Team, "Evaluation of first power simulation-The New Line Copenhagen Ringsted Alignment and Railway Technology." Copenhagen, Denmark, February 2013.

[3] IEC/TR 61000-3-13: Limits - Assessment of emission limits for the connection of unbalanced installations to $\mathrm{MV}, \mathrm{HV}$ and $\mathrm{EHV}$ power systems, 2008.

[4] Mohsen Kalantari, Muhammad Javad Sadeghi, Seyed Saeed Fazel, Siamak Farshad. "Investigation off Power Factor Behaviour in AC Railway System Based on Special Traction Transformers." Tehran, Iran, September 2010.

[5] Meo, Santolo. "The International Review on Modelling and Simulations (IREMOS)." Naples, Italy, February 2011.

[6] R.Grünbaum, J.-P Hasler and B. Thorvaldsson. FACTS: Powerful Means for Dynamic Load Balancing and Voltage Support of AC Traction Feeders. Porto, 2001.

[7] Voltage Unbalance: Power Quality Issues, Related Standards and Mitigation Techniques: Effect of unbalanced voltage on end use equipment performance, EPRI, Palo Alto, CA: 2000 . 